\title{
Using convective flow splitting for the direct printing of fine copper lines
}

\author{
Tanja Cuk \\ Department of Electrical Engineering, Princeton University, Princeton, New Jersey 08544-5263
}

Sandra M. Troian ${ }^{\text {a) }}$

Interfacial Science Laboratory, Department of Chemical Engineering, Princeton University, Princeton, New Jersey 08544-5263

\author{
Cheong Min Hong and Sigurd Wagner \\ Department of Electrical Engineering and Center for Photonics and Opto-Electronic Materials, \\ Princeton University, Princeton, New Jersey 08544-5263
}

(Received 4 January 2000; accepted for publication 2 August 2000)

\begin{abstract}
Liquid ribbons of solutions of copper hexanoate in a volatile solvent were drawn on a glass slide using either fine glass capillaries or an ink jet printer. After solvent evaporation, the solute was observed to segregate into multiple pairs of stripes much narrower than the initial ribbon diameter. These stripes were then converted to pure copper by annealing. Surface profiles indicate that the thickness, width, and number of lines formed are strongly dependent on the solution viscosity and volume per unit length deposited. From flow visualization studies and surface profiling, we have found that evaporative cooling produces Bénard-Marangoni convection patterns which accrete the solute along two key boundaries of the flow, namely the three phase contact line and the outer edge of a stagnant region about the ribbon apex. These findings suggest that optimization of the deposition and evaporation process can be used to "write" fine metallic lines from a wider liquid precursor. (C) 2000 American Institute of Physics. [S0003-6951(00)00939-6]
\end{abstract}

In recent years, innovative stamping and printing techniques ${ }^{1-8}$ have been developed as alternatives to patterning metallic films by photolithography. In a recent study, we reported the use of a commercial ink jet printer to form pure copper lines with a resistivity of $10 \mu \Omega \mathrm{cm}$. A solution of copper hexanoate, $\mathrm{Cu}_{2}\left(\mathrm{OH}_{2}\right)_{2}\left(\mathrm{O}_{2} \mathrm{CR}\right)_{4}$ with $\mathrm{R}=\left(\mathrm{CH}_{2}\right)_{4} \mathrm{CH}_{3}$, in isopropanol or chloroform, was jetted onto a thin glass foil ${ }^{9}$ and reduced to pure metallic form by annealing. ${ }^{10}$ Since commercial printers offer little flexibility in the choice of solvent, range of solute concentrations, and volume ejected, for this study we have also written liquid lines with glass capillaries of inner diameter approximately $100 \mu \mathrm{m}$.

Using either deposition method, we have observed that while drying, the copper hexanoate $(\mathrm{CuHex})$ accretes into one or two pairs of parallel lines narrower in width than the original liquid ribbon. Figure 1 shows a pair of converted copper lines "written" by each method. Our results indicate that the solution viscosity and volume per unit length deposited determine the thickness, width, and number of solid lines formed from a single liquid precursor. Our flow visualization studies identify Bénard-Marangoni convection ${ }^{11}$ as the mechanism responsible for the formation of multiple solid lines from a single liquid line. Based on this flow pattern, which traps the majority of solute along two key boundaries, we propose which critical parameters can be enlisted to achieve self-organized line narrowing. Optimization and control of this phenomenon can be used for the direct printing of fine metallic lines or rings at high resolution.

We studied the drying behavior of three concentrations, $C=0.02,0.06$, and $0.10 \mathrm{~g} / \mathrm{ml} \mathrm{CuHex} / \mathrm{CHCl}_{3}$, prepared by

\footnotetext{
a) Author to whom correspondence should be addressed; electronic mail: stroian@princeton.edu
}

dissolving $\mathrm{CuHex}$ in chloroform $\left(\mathrm{CHCl}_{3}\right)$ and heating for two minutes at $63^{\circ} \mathrm{C}$. The solution filled a fine capillary which was used to write a liquid ribbon or droplet on a leveled glass slide. The solvent rapidly evaporated leaving characteristic stripe or ring patterns on the glass surface. The lines which formed were always parallel to the contact line (i.e., the vapor-liquid-solid boundary) for either geometry. In this letter, we mostly discuss the ribbon geometry of interest for printing thin copper lines; in cross section, either geometry produces the same solute accretion patterns. A Dektak profilometer was used to obtain cross-sectional scans of the dried solid lines. The more viscous solutions poured and spread more slowly on the glass slide thereby decreasing the volume per unit length dispensed as the capillary was drawn across the substrate. The vol/length $(\mathrm{ml} / \mathrm{cm})$ was estimated from the ratio $\rho A_{\mathrm{CuHex}} / C$ where $\rho=1.1 \mathrm{~g} / \mathrm{ml}$ is the density of CuHex, $A_{\mathrm{CuHex}}$ the integrated cross-sectional area of dried CuHex as measured by the profilometer, and $C$ the initial

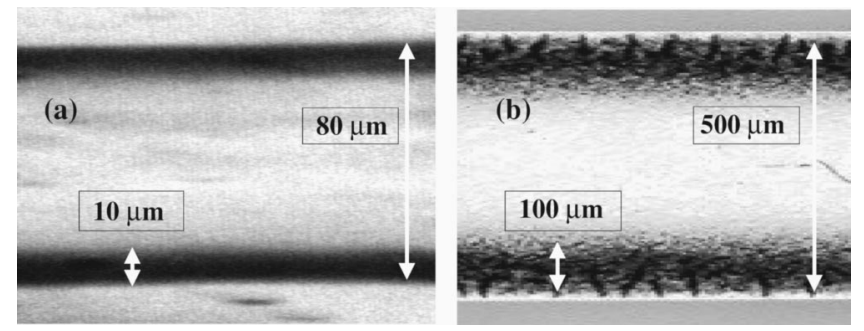

FIG. 1. Lines of copper metal formed by evaporative accretion and annealing. (a) Transmission photograph of two copper lines, each $10 \mu \mathrm{m}$ in width, formed by ink jetting an $80-\mu \mathrm{m}$-wide liquid ribbon of $0.10 \mathrm{~g} \mathrm{CuHex} / \mathrm{ml}$ isopropanol onto a glass foil. (b) Optical micrograph of two copper lines, each $100 \mu \mathrm{m}$ in width, formed by capillary writing a 544- $\mu \mathrm{m}$-wide liquid ribbon of $0.10 \mathrm{~g} \mathrm{CuHex} / \mathrm{ml} \mathrm{CHCl}_{3}$ onto a glass slide (Ref. 25). 
TABLE I. Parameter values for the writing of copper lines by the capillary method. Profiles corresponding to the entries 1a-1c are shown in Fig. 2.

\begin{tabular}{|c|c|c|c|c|c|}
\hline Expt. & $\begin{array}{c}C \\
\mathrm{~g} / \mathrm{ml}\end{array}$ & $\begin{array}{c}\mu \\
\mathrm{Pa} \mathrm{s} \\
\left(10^{-4}\right)\end{array}$ & $\begin{array}{c}\text { Vol/length } \\
\mathrm{ml} / \mathrm{cm} \\
\left(10^{-5}\right)\end{array}$ & $\begin{array}{c}\theta \\
\text { degrees }\end{array}$ & $\begin{array}{c}\text { Ribbon width } \\
\mu \mathrm{m}\end{array}$ \\
\hline control & 0.00 & 5.37 & $\ldots$ & 8.0 & $\cdots$ \\
\hline $1 \mathrm{a}$ & 0.100 & 30.65 & 15.5 & 17.8 & 544 \\
\hline $1 \mathrm{~b}$ & 0.060 & 10.67 & 16.7 & 15.5 & 605 \\
\hline $1 \mathrm{c}$ & 0.021 & 6.56 & 22.3 & 12.5 & 780 \\
\hline $2 \mathrm{a}$ & 0.102 & 30.65 & 3.78 & 6.9 & 434 \\
\hline $2 b$ & 0.063 & 10.67 & 6.27 & 4.0 & 741 \\
\hline $2 \mathrm{c}$ & 0.021 & 6.56 & 8.7 & 3.3 & 955 \\
\hline $3 a$ & 0.062 & 10.7 & 3.9 & 7.0 & 436 \\
\hline $3 \mathrm{~b}$ & 0.062 & 10.7 & 48.0 & 14.4 & 1070 \\
\hline
\end{tabular}

solute concentration. This estimate was used to evaluate the initial contact angle, $\theta$, of the liquid ribbon against the glass surface. Listed in Table I are values for the initial concentration, viscosity, volume/length, contact angle, and ribbon width for eight experiments.

Figure 2 shows typical transverse scans of dried solute profiles for three concentrations. The corresponding parameter values are given by entries $1 \mathrm{a}-1 \mathrm{c}$ in Table I. The less viscous the solution, the larger the volume per unit length dispensed and the smaller the initial contact angle. The least concentrated solution, $C=0.02 \mathrm{~g} / \mathrm{ml}$, produced the widest $(780 \mu \mathrm{m})$ and thinnest dried ribbon. This ribbon split into four parallel lines while drying, as evident from the four peaks shown in Fig. 2. The exterior pair averaged $0.8 \mu \mathrm{m}$ in height and $30 \mu \mathrm{m}$ in width and the interior pair averaged 1.7 $\mu \mathrm{m}$ in height and $45 \mu \mathrm{m}$ in width. (The linewidths refer to the width at half maximum as measured above the highest neighboring baseline value.) The highest concentration, $C$ $=0.10 \mathrm{~g} / \mathrm{ml}$, instead produced a $544-\mu \mathrm{m}$-width dried ribbon which split into a single line pair measuring $4.1 \mu \mathrm{m}$ in height and $104 \mu \mathrm{m}$ in width. The concentration $C=0.06 \mathrm{~g} / \mathrm{ml}$ produced a $605-\mu \mathrm{m}$-wide ribbon which split into a strong exterior pair and an incipient second internal pair, a behavior intermediate between $C=0.10$ and $0.02 \mathrm{~g} / \mathrm{ml}$. These same trends were observed for entries $2 \mathrm{a}-2 \mathrm{c}$ in Table I. In addi-

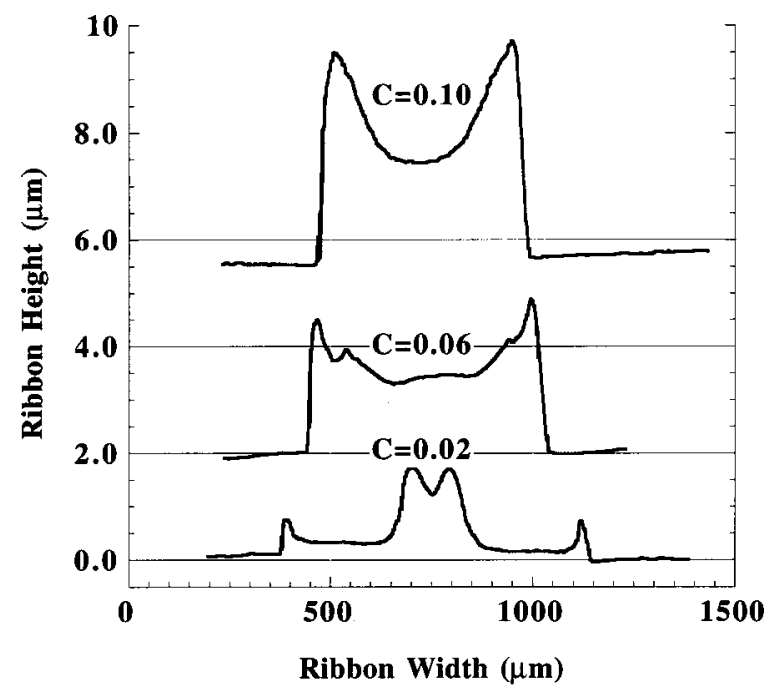

FIG. 2. Surface profiles of dried CuHex from precursor liquid ribbons with $C=0.10,0.06$, and $0.02 \mathrm{~g} / \mathrm{ml}$. Other relevant parameter values are listed in

entries 1a-1c of Table I.
Downloaded 15 Sep 2006 to 131.215.240.9. Redistribution subject to AIP license or copyright, see http://apl.aip.org/apl/copyright.jsp

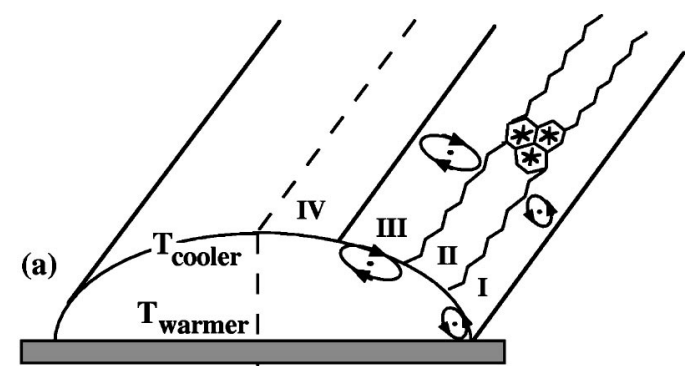

(b)

I

FIG. 3. (a) Flow regimes observed in an evaporating liquid ribbon of chloroform or chloroform with CuHex. Regions I and III display BénardMarangoni convective rolls (oppositely directed), region II displays a strip of hexagonal Bénard cells, and region IV presents a stagnant strip with no perceptible surface motion which surrounds the liquid apex. (b) Typical dried accretion patterns for lower concentration (less viscous) systems. Diagram not drawn to scale.

tion, studies performed at constant concentration but different sized capillaries (Table I, Expt. 3a and 3b) showed that the larger the dispensed volume per unit length and therefore the wider the dried ribbon, the more pairs of solid lines formed. At $48 \mathrm{ml} / \mathrm{cm}$, there developed four distinct solid lines, an exterior pair measuring $4.0 \mu \mathrm{m}$ in height and $42 \mu \mathrm{m}$ in width and an interior pair averaging $4.3 \mu \mathrm{m}$ in height and $170 \mu \mathrm{m}$ in width. At $3.9 \mathrm{ml} / \mathrm{cm}$, there only formed one exterior line pair averaging $0.9 \mu \mathrm{m}$ in height and $63 \mu \mathrm{m}$ in width and an unresolved, single central peak $0.6 \mu \mathrm{m}$ in height and $210 \mu \mathrm{m}$ in width. Clearly the less viscous the solution, the faster the spreading during evaporation and the increased propensity for the formation of two line pairs.

Controlling the flow patterns induced by evaporation requires knowledge of the mechanism governing solute localization and accretion. It has recently been reported that evaporating droplets containing passive flow markers like polystyrene spheres produce distinct ring stain patterns at the drop periphery ${ }^{12-17}$ caused by contact line pinning. Numerical ${ }^{18-20}$ and experimental studies ${ }^{21-23}$ of small and highly volatile droplets like chloroform evaporating in air at room temperature have also shown that evaporative cooling creates Bénard-Marangoni ${ }^{11}$ (i.e., surface tension dominated) convection patterns above the critical Marangoni number. ${ }^{24}$ Both cylindrical rolls and polygonal cells have been observed.

We used video microscopy to track the flow patterns of micron sized silica beads dispersed in chloroform ${ }^{25}$ and $\mathrm{Cu}$ Hex in chloroform $(C=0.002 \mathrm{~g} / \mathrm{ml})$ to determine the source of the metallic stripes shown in Figs. 1 and 2. Figure 3 depicts a sketch of (a) the four distinct flow regimes observed in an evaporating liquid ribbon at intermediate times and (b) the location of the CuHex solute peaks after drying. The circulating flow established in the convective rolls occupying regions I and III is oppositely directed. Polygonal Bénard cells, including hexagonal ones, develop in region II. Despite the vigorous flow patterns nearby, a stripe of liquid with no perceptible surface motion always develops in region IV. All the solute in region IV dries out of solution plating the ribbon central region with a thin CuHex film. We have observed that solute first accretes at the pinned contact line. It remains unclear whether this deposition is governed by loAIP license or copyright, see http://apl.aip.org/apl/copyright.jsp 
calized self-trapping and aggregation or whether the convective flow in region I enables and assists this process. Additional material also accretes at the junction between III and IV because of the clockwise flow and trapping at the edge of the stagnant strip. As the ribbon height decreases, the Young force balance is exceeded and the contact line depins from its original position. During the evaporation process, regions I and II grow and migrate inward at the expense of region III. The solute contained in regions I-III is finally forced to collect against the edge of the stagnant strip. Measurements of the final location of the dried patterns corresponds well with the initial position of the contact line and the edge of the stagnant cap. While there is additional material deposited in the interstitial regions as shown in Fig. 2, these can be etched away during processing to leave only the marked lines shown in Fig. 3(b).

Flow visualization is compromised at the higher concentrations listed in Table I; however, the location of the single wide pair of dried lines is consistent with the location of the outer line pairs formed in experiments with flow markers at lower concentrations. We have observed the stagnant strip and region I even at the higher concentrations; regions II and III are not so evident and are not required for solute accretion at the contact line. It is unknown whether regions II and/or III are altogether absent at higher concentrations or whether the longer pinning times allow more solute accretion near the contact line and less flow migration toward the ribbon center.

In summary, our results indicate that the lowest viscosity solutions easily depin from the original contact line leaving deposits at the contact line and also at the boundary of regions III and IV. The lower (higher) the concentration, the faster (slower) the depinning, and the less (more) solute deposited at the contact line. Of particular interest is whether narrower stripes or rings dried patterns can be formed by this method and whether an initial flat liquid profile would produce more than two lines pairs, as observed in classic Bénard experiments for uniform liquid layers heated from below. ${ }^{26}$ We expect thinner liquid layers to form narrower metallic lines provided the critical Marangoni number is exceeded. Further quantification of the critical parameters controlling the number, width, and resistivity of metal lines produced by this novel technique, as well as flow simulations of evaporating films with a uniform height profile, provide the basis for our next study.

Financial support from the DARPA-ETO Molecular Level Printing program (S.M.T. and S.W.) and a National Science Foundation CAREER award (S.M.T.) are gratefully acknowledged. Alex Furman assisted in the ink-jet experiments.
${ }^{1}$ X. N. Xia and G. M. Whitesides, Annu. Rev. Mater. Sci. 28, 153 (1998) and references therein.

${ }^{2}$ S. Y. Chou, P. R. Krauss, and P. J. Renstrom, J. Vac. Sci. Technol. B 14, 4129 (1996) and references therein.

${ }^{3}$ A. Kumar and G. Whitesides, Appl. Phys. Lett. 63, 2002 (1993).

${ }^{4}$ R. J. Jackman, J. L. Wilbur, and G. M. Whitesides, Science 269, 664 (1995).

${ }^{5}$ Y. Mikami, Y. Nagae, Y. Mori, K. Kuwabara, T. Saito, H. Hayama, H. Asada, Y. Akimoto, M. Kobayashi, S. Okazaki, K. Asaka, H. Matsui, K. Nakamura, and E. Kaneko, IEEE Trans. Electron Devices 41, 306 (1994).

${ }^{6}$ H. A. Biebuyck, N. B. Larsen, E. Delamarche, and B. Michel, IBM J. Res. Dev. 41, 159 (1997).

${ }^{7}$ L. Libioulle, A. Bietsch, H. Schmid, B. Michel, and E. Delamarche, Langmuir 15, 300 (1999).

${ }^{8}$ J. P. Bourgoin and S. Palacin, Langmuir 14, 3967 (1998).

${ }^{9}$ C. M. Hong and S. Wagner, Mater. Res. Soc. Symp. Proc. 558, 387 (2000).

${ }^{10}$ C. M. Hong, H. Gleskova, and S. Wagner, Mater. Res. Soc. Symp. Proc. 471, 35 (1997).

${ }^{11}$ R. F. Probstein, Physicochemical Hydrodynamics, 2nd ed. (Wiley, New York, 1994), Chap. 10 and references therein.

${ }^{12}$ E. Adachi, A. S. Dimitrov, and K. Nagayama, Langmuir 11, 1057 (1995).

${ }^{13}$ E. Parisse and C. Allain, J. Phys. II 6, 1111 (1996).

${ }^{14}$ J. Conway, H. Korns, and M. R. Fisch, Langmuir 13, 426 (1997).

${ }^{15}$ R. D. Deegan, O. Bakajin, T. F. Dupont, G. Huber, S. R. Nagel, and T. A. Witten, Nature (London) 389, 827 (1997).

${ }^{16}$ S. Maenosono, C. D. Dushkin, S. Saita, and Y. Yamaguchi, Langmuir 15, 957 (1999).

${ }^{17}$ R. D. Deegan, Phys. Rev. E 61, 475 (2000).

${ }^{18}$ J. C. Duh and W. J. Yang, Numer. Heat Transfer, Part A 16, 129 (1989).

${ }^{19}$ H. Niazmand, B. D. Shaw, H. A. Dwyer, and I. Aharon, Combust. Sci. Technol. 103, 219 (1994).

${ }^{20}$ A. T. Shih and C. M. Megaridis, Int. J. Heat Mass Transf. 39, 247 (1995).

${ }^{21}$ N. Zhang and W. J. Yang, Trans. ASME 104, 656 (1982).

${ }^{22}$ N. Zhang and W. J. Wang, Exp. Fluids 1, 101 (1983).

${ }^{23}$ N. Zhang and W. J. Wang, Trans. ASME 106, 652 (1984).

${ }^{24}$ For a liquid ribbon with cylindrical cap cross section, the Rayleigh number $R a$, which describes the competition between buoyancy driven convection, viscous shear, and thermal diffusion, is defined as $R a$ $=\left(\beta g \Delta T R^{3}\right) / \nu \alpha$, where $\beta$ is the thermal expansion coefficient, $g$ the gravitational constant, $\Delta T$ the maximum temperature variation across the liquid film, $R$ the initial ribbon radius, $\nu$ the liquid kinematic viscosity, and $\alpha$ the thermal diffusivity. The Marangoni number $M a$, which describes the competition between shear driven flow caused by surface tension gradients, viscous shear, and thermal diffusion, is defined as $M a$ $=\left(\sigma_{T} \Delta T R\right) / \mu \alpha$, where $\sigma_{T}$ denotes the variation in surface tension with temperature and $\mu$ the liquid viscosity. In our studies, the ratio $M a / R a$ exceeds $10^{6}$. The flow is therefore completely driven by Marangoni stresses.

${ }^{25}$ According to Zhang and Wang (1982), chloroform is a "substable" solvent. During evaporation, a droplet of substable liquid will develop a distinct outer rim with crosswise striations. These striations result from a secondary instability which produces polygonal Bénard-Marangoni cells, as depicted in region II of Fig. 3. These remnant striations, which appear as black hatchmarks in Fig. 1(b), can be eliminated by using "stable" solvents or longer annealing times.

${ }^{26}$ T. E. Faber, Fluid Dynamics for Physicists (Cambridge University Press, Cambridge, 1995), Chap. 8. 